\section{JTI}

JOURNAL OF

TRAUMA AND INJURY

\title{
Pitfalls, Complications, and Necessity of Education about REBOA: A Single Regional Trauma Center Study
}

\author{
Sol Kim, M.D. ${ }^{1}$, Jae Sik Chung, M.D. ${ }^{1,2}$, Sung Woo Jang, M.D. ${ }^{1,2}$, \\ Pil Young Jung, M.D., Ph.D., ${ }^{1,2}$ \\ ${ }^{1}$ Department of Surgery, Yonsei University Wonju College of Medicine, Wonju, Korea \\ ${ }^{2}$ Regional Trauma Center, Wonju Severance Christian Hospital, Wonju, Korea
}

Received: September 15, 2020

Revised: September 24, 2020

Accepted: September 24, 2020

\section{Correspondence to}

Pil Young Jung, M.D., Ph.D.

Regional Trauma Center, Wonju Severance Christian Hospital, Department of Surgery,

Yonsei University Wonju College of Medi-

cine, 20 IIsan-ro, Wonju 26426, Korea

Tel: $+82-33-741-0573$

Fax: +82-33-741-0574

E-mail: surgery4trauma@yonsei.ac.kr
Purpose: Resuscitative endovascular balloon occlusion of the aorta (REBOA) is an emergency procedure and extremely time-dependent, and the proficiency of the physician is important. Due to a lack of REBOA education programs in Republic of Korea, few physicians have been trained in the procedure. In this study, we examined how REBOA education affects clinical outcomes in a single center.

Methods: A retrospective study conducted from February 2017 to June 2020 at a regional trauma center. We collected data of patients who underwent REBOA and analyzed the factors that influenced the outcome. The patients were divided into the educated and non-educated groups (based on REBOA training received by their physicians), and the success and failure groups.

Results: A total of 24 patients underwent REBOA during the study. There were eight patients in the success group and 16 patients in the failure group. There are no significant differences between the educated and non-educated groups in sex, age, ISS, shock, injury-to-REBOA time, injury mechanism, injury sites, arrest, access site, type of catheter, type of REBOA, target Zone, mortality, and the result of REBOA. The non-educated group had a higher risk for failure compared to the educated group in multivariate analysis (odds ratio [OR] 154.64, 95\% confidence interval [CI] 1.11-22.60).

Conclusions: Failure in REBOA is harmful to patients. The risk of failure is increased in the non-educated group. Physicians working in the trauma center or emergency department need to complete the REBOA education program.

Keywords: Balloon occlusion; Aorta; Trauma centers 


\section{INTRODUCTION}

Non-compressible torso hemorrhage is one of the leading causes of potentially preventable trauma deaths [1-3]. Approximately, $30-40 \%$ of traumatic patients die from hemorrhage [4]. Globally, 1,481,700 people die from traumatic hemorrhage each year, and the years of life lost from traumatic hemorrhage amount to $74,568,000$ years [5]. Consequently, hemostasis is the most important strategy in the care of patients with severe trauma [6]. Open aortic cross-clamping (OACC) has been used for trauma patients with torso hemorrhage [7]. In recent years, it has been argued that resuscitative endovascular balloon occlusion of the aorta (REBOA) can replace OACC in selective cases [8,9]. In Republic of Korea, most trauma patients are affected by blunt traumas (90.8\% of reported patients). In particular, REBOA plays an important role in patients with hemorrhagic shock [10].

REBOA involves temporary placement of a balloon in the aorta to block the proximal portion of the bleeding site $[3,11-13]$. REBOA is less invasive compared to OACC and may provide similar physiological results [14]. Despite these benefits, REBOA is not widely used, due to lack of understanding of the procedure, lack of skills, and potential complications associated with the procedure $[3,11,12]$. Some of the known complications of REBOA include aortic occlusion, postoperative thrombosis, and limb amputation [15].

Since REBOA is an emergency procedure and extremely time-dependent [3], the proficiency of the physician is important. However, only a few have been trained in REBOA because of the lack of education programs for REBOA in Republic of Korea.

In this study, we examined how education for REBOA affects the outcomes in a single center. Patients who received REBOA in a single institution were targeted. The survey focused on the clinical outcomes, categorized by physicians who were educated in REBOA and those who were not. We hypothesized that there would be fewer complications in physicians trained in REBOA.

\section{Endovascular training for REBOA (ET-REBOA)}

Endovascular training for REBOA (ET-REBOA) is a training program for REBOA in Republic of Korea. In the early period, REBOA was limited due to the lack of $7 \mathrm{Fr}$ catheters, and there was no choice but to use a $14 \mathrm{Fr}$ sheath or a $12 \mathrm{Fr}$ hard balloon. In recent years, clinical applications of the 7 Fr catheters have increased, and good results for patient survival have been reported $[16,17]$. Therefore, ET-REBOA was created by Group for Resuscitative Endovascular and Advanced Treatment on Trauma (GREAT) for REBOA education. ET-REBOA was first started in May 2018 and is currently being implemented as a Korean Association for Research, Procedures, and Education on Trauma (KARPET) education program (http://karpet.or.kr).

\section{METHODS}

\section{Population}

This study was a retrospective study conducted from February 2017 to June 2020 at a regional trauma center belonging to tertiary medical institutions in the Gangwon province, Republic of Korea. We collected data of patients who underwent REBOA using the registry of a Yonsei University Wonju Severance Christian Hospital. The patients were divided into two groups based on training received by their attending physicians (educated and non-educated) for comparative analysis. The educated group consisted of patients who received REBOA from trauma surgeons who completed training in REBOA, while the non-educated group included patients who received REBOA from physicians who did not complete training in REBOA. Demographic data, Injury Severity

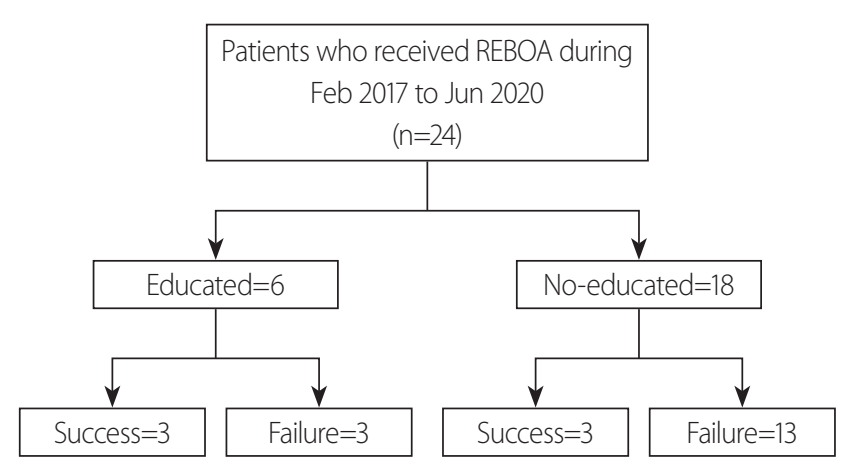

Fig. 1. Flowchart of this study. REBOA: resuscitative endovascular balloon occlusion of the aorta. 
Table 1. Patient characteristics according to education status

\begin{tabular}{|c|c|c|c|c|}
\hline & Total $(n=24)$ & Educated $(n=6)$ & Non-educated $(n=18)$ & $p$-value \\
\hline Sex & & & & 1.000 \\
\hline Male & $12(50.0)$ & $3(50.0)$ & $9(50.0)$ & \\
\hline Female & $12(50.0)$ & $3(50.0)$ & $9(50.0)$ & \\
\hline Age & $52.8 \pm 17.6$ & $62.3 \pm 14.3$ & $49.6 \pm 17.8$ & 0.127 \\
\hline ISS & $29.7 \pm 18.9$ & $35.2 \pm 26.4$ & $27.9 \pm 16.2$ & 0.425 \\
\hline Shock & $20(83.3)$ & $5(83.3)$ & $15(83.3)$ & 1.000 \\
\hline Injury-to-REBOA time & $173.9 \pm 114.9$ & $217.2 \pm 142.1$ & $159.4 \pm 105.1$ & 0.297 \\
\hline Injury mechanism & & & & 0.204 \\
\hline Crush & $1(4.2)$ & $0(0.0)$ & $1(5.6)$ & \\
\hline Fall & $5(20.8)$ & $0(0.0)$ & $5(27.8)$ & \\
\hline In-car TA & $7(29.2)$ & $2(33.3)$ & $5(27.8)$ & \\
\hline Motorcycle TA & $3(12.5)$ & $0(0.0)$ & $3(16.7)$ & \\
\hline Pedestrian TA & $7(29.2)$ & $4(66.7)$ & $3(16.7)$ & \\
\hline Not-trauma & $1(4.2)$ & $0(0.0)$ & $1(5.6)$ & \\
\hline \multicolumn{5}{|l|}{ Injury sites ${ }^{\mathrm{a}}$} \\
\hline Multiple & $6(25.0)$ & $1(16.7)$ & $5(27.8)$ & 1.000 \\
\hline Liver & $5(20.8)$ & $0(0.0)$ & $5(27.8)$ & 0.384 \\
\hline Spleen & $1(4.2)$ & $1(16.7)$ & $0(0.0)$ & 0.555 \\
\hline Kidney & $2(8.3)$ & $0(0.0)$ & $2(11.1)$ & 1.000 \\
\hline Inferior vena cava & $2(8.3)$ & $0(0.0)$ & $2(11.1)$ & 1.000 \\
\hline Mesentery & $4(16.7)$ & $2(33.3)$ & $2(11.1)$ & 0.527 \\
\hline Artery $^{b}$ & $3(12.5)$ & $0(0.0)$ & $3(16.7)$ & 0.546 \\
\hline Pelvis & $11(45.8)$ & $4(66.7)$ & $7(38.9)$ & 0.478 \\
\hline Leg & $2(8.3)$ & $0(0.0)$ & $2(11.1)$ & 1.000 \\
\hline Arrest & $11(45.8)$ & $1(16.7)$ & $10(55.6)$ & 0.237 \\
\hline Access site & & & & 1.000 \\
\hline Right femoral artery & 17 (70.8) & $4(66.7)$ & $13(72.2)$ & \\
\hline Left femoral artery & $7(29.2)$ & $2(33.3)$ & $5(27.8)$ & \\
\hline Type of catheter & & & & 0.088 \\
\hline $12 \mathrm{Fr}$ & $9(37.5)$ & $0(0.0)$ & $9(50.0)$ & \\
\hline $7 \mathrm{Fr}$ & $15(62.5)$ & $6(100.0)$ & $9(50.0)$ & \\
\hline Type of REBOA & & & & 0.339 \\
\hline Partial occlusion & $10(41.7)$ & $4(66.7)$ & $6(33.3)$ & \\
\hline Total occlusion & $14(58.3)$ & $2(33.3)$ & $12(66.7)$ & \\
\hline Target zone & & & & 0.637 \\
\hline 1 & $12(50.0)$ & $4(66.7)$ & $8(44.4)$ & \\
\hline 3 & $12(50.0)$ & $2(33.3)$ & $10(55.6)$ & \\
\hline Mortality & $18(75.0)$ & $4(66.7)$ & $14(77.8)$ & 1.000 \\
\hline Result of REBOA & & & & 0.617 \\
\hline Success & $8(33.3)$ & $3(50.0)$ & $5(27.8)$ & \\
\hline Fail & $16(66.7)$ & $3(50.0)$ & $13(72.2)$ & \\
\hline
\end{tabular}

Values are presented as mean \pm standard deviation or number (\%).

ISS: injury severity score, REBOA: resuscitative endovascular balloon occlusion of the aorta, TA: traffic accident.

aDuplicated.

${ }^{\mathrm{b}}$ Abdominal aorta injury, proper hepatic artery injury, liac artery injury. 
Score (ISS), shock (SBP $<80 \mathrm{mmHg}$ ), injury-to-REBOA time, injury mechanism, injury sites, arrest, access site, type of catheter, type of REBOA (partial or total occlusion), target Zone, and mortality result of REBOA were obtained from the patients' electronic medical records. SBP was recorded as the moment when the trauma surgeon decided to perform REBOA. The mechanism of injury were classified as crush injuries, fall, in-car traffic accidents (TA), motorcycle TA, and pedestrian TA.

\section{REBOA}

All patients received REBOA in-hospital. Most of the cases of REBOA were performed by the trauma surgeon on duty, but two cases were performed by an emergency physician. For the procedure, a 12 Fr or 7 Fr catheter was used. In all cases, the access site was the femoral artery, including both the left and right femoral arteries. The REBOA Zone was confirmed via X-ray or ultrasonography. Total or partial occlusion was performed depending on the patient's condition. The injury-to-REBOA time was defined as the time of the accident to the time when the REBOA balloon was first inflated. When the REBOA balloon was located outside the desired targeted Zone during the first procedure, we recorded it as a failure. When an arrest occurred before REBOA was performed, we recorded it as an arrest.

\section{Statistical analysis}

All statistical analyses were performed using R Statistical Software (version 3.6.3; R Foundation for Statistical Computing, Vienna, Austria). The sample population followed a normal distribution, which was confirmed using the Shapiro-Wilk test. For the comparative analyses between the two groups, the Student t-test was used for continuous variables and the Fisher's exact test was used to compare categorical variables. A logistic regression analysis (LRA) model was used to determine whether the success of REBOA was a dependent variable. LRA was performed as univariate and multivariate analyses. The independent variables of the LRA model were sex, age, ISS, injury-to-REBOA time, arrest, access site, type of catheter, target Zone, and education. All results of LRA were expressed as odds ratios (ORs) and 95\% confidence intervals (CIs). The LRA model for all statistical analyses, $p<0.05$ was considered statistically significant.

Table 2. Description for failure of REBOA

\begin{tabular}{|c|c|c|c|c|c|c|}
\hline No & Sex/age & Reason of REBOA & Education & Target zone & Result of REBOA & Mortality \\
\hline 1 & $M / 58$ & Pseudoaneurysm of abdominal aorta & No & 1 & REBOA was not function & Death \\
\hline 2 & $F / 54$ & Liver injury & No & 1 & Placed in Zone 2 & Survival \\
\hline 3 & $F / 70$ & IVC injury, mesentery injury & No & 1 & Placed in Zone 2 & Death \\
\hline 4 & $M / 18$ & Liver injury, proper hepatic artery injury & No & 1 & Placed in Zone 2 & Death \\
\hline 5 & $F / 53$ & IVC injury & No & 1 & Placed in Zone 2 & Death \\
\hline 6 & M/55 & Liver injury, kidney injury & No & 1 & Placed in Zone 2 & Death \\
\hline 7 & $F / 73$ & Pelvic bone fracture, spleen injury & Yes & 1 & Placed in Zone 2 & Death \\
\hline 8 & $\mathrm{M} / 70$ & \|liac artery injury & Yes & 1 & Placed outside the aorta & Death \\
\hline 9 & $F / 16$ & Pelvic bone fracture & No & 3 & Placed in the right common carotid artery & Death \\
\hline 10 & $M / 51$ & Pelvic bone fracture & No & 3 & Placed in Zone 2 & Death \\
\hline 11 & $M / 66$ & Pelvic bone fracture & Yes & 3 & Placed in Zone 2 & Death \\
\hline 12 & $\mathrm{M} / 77$ & Pelvic bone fracture & No & 3 & Placed in Zone 2 & Death \\
\hline 13 & $\mathrm{~F} / 52$ & Pelvic bone fracture & No & 3 & Placed in Zone 2 & Death \\
\hline 14 & $F / 43$ & Pelvic bone fracture & No & 3 & Placed in below the iliac bifurcation & Survival \\
\hline 15 & M/52 & Both leg injury & No & 3 & Placed in below the iliac bifurcation & Survival \\
\hline 16 & $\mathrm{M} / 58$ & Pelvic bone fracture & No & 3 & Placed in inferior vena cava & Death \\
\hline
\end{tabular}

REBOA: resuscitative endovascular balloon occlusion of the aorta, IVC: inferior vena cava, M: male, F: female. 


\section{RESULTS}

\section{Patient selection and characteristics}

A total of 24 patients underwent REBOA during the study. The patinents were categorized into the success and failure groups. There were eight patients in the success group and 16 patients in the failure group. The patient flowchart is summarized in Fig. 1. The success of REBOA was not statistically different between the two groups (Fisher's exact test; $p=0.617$ ).

Other patient characteristics according to the education status are summarized in Table 1. There were no significant differences between the educated and non-educated groups in terms of patients' characteristics: sex ( $p=1.000)$, age $(p=0.127)$, ISS $(p=0.425)$, shock $(p=1.000)$, injury-to-REBOA time $(p=0.297)$, injury mechanism ( $p=0.204)$, arrest $(p=0.237)$, access site $(p=1.000)$, type of catheter $(p=0.088)$, type of REBOA ( $p=0.339)$, target Zone ( $p=0.637)$, mortality $(p=1.000)$, and result of REBOA ( $p=0.617$ ). There was one case which involved a non-trauma patient. In this case, REBOA was performed during surgery due to a pseudoaneurysm of the abdominal aorta in the previously performed abdominal aortic graft.

There were a total of 16 failed cases (Table 2). Most of the cases were placed in Zone 2. There were a total of six cases of unique failure. In the education group, three cases failed. Two of them were cases that were placed in Zone 2, and the other involved the catheter balloon coming out of the artery due to an iliac artery injury.

\section{Logistic regression analysis model}

Univariate and multivariate LRA was performed to determine success vs. failure. Sex (males vs. females) was not statistically significant in both univariate (OR 2.14, 95\% CI 0.39-13.61) and multivariate (OR 1.48, 95\% CI 0.1123.68) analyses. Age was also not statistically significant (univariate analysis: OR 1.01, 95\% CI 0.96-1.07; multivariate analysis: OR $1.09,95 \%$ CI $0.98-1.30$ ). ISS was not statistically significant in both univariate (OR 0.98, 95\% CI 0.93-1.02), and multivariate (OR 0.98, 95\% CI 0.91$1.05)$ analyses. Injury-to-REBOA time was not statistically significant in both univariate (OR 1.00, 95\% CI 0.99-1.00) and multivariate (OR 1.00, 95\% CI 0.99-1.02) analyses. The arrest group was not statistically significant compared to the non-arrest group in both univariate (OR 3.86, 95\% CI 0.65-32.36), and multivariate (OR 3.31, 95\% CI 0.14183). There is no statistically significant in the right femoral artery accessed group compared to the left femoral artery accessed group in both univariate (OR $0.56,95 \%$ CI 0.09-3.68) and multivariate (OR 1.29, 95\% CI 0.07-42.14) analysis. The $7 \mathrm{Fr}$ catheter tended to be more successful than the 12 Fr catheter according to the multivariate analysis (OR 0.01, 95\% CI 0.00-0.68), but not in univariate analysis (OR 0.45, 95\% CI 0.07-2.63). The group with a target Zone of 3 was also not statistically significant compared to the group with a target Zone of 1 in both

Table 3. The logistic regression analysis model with procedural failure

\begin{tabular}{|c|c|c|}
\hline & Univariate & Multivariate \\
\hline \multicolumn{3}{|l|}{ Sex } \\
\hline Female & Ref & Ref \\
\hline Male & $2.14(0.39-13.61)$ & $1.48(0.11-23.68)$ \\
\hline Age & $1.01(0.96-1.07)$ & $1.09(0.98-1.3)$ \\
\hline ISS & $0.98(0.93-1.02)$ & $0.98(0.91-1.05)$ \\
\hline Injury to REBOA time & $1(0.99-1)$ & 1 (0.99-1.02) \\
\hline \multicolumn{3}{|l|}{ Arrest } \\
\hline No & Ref & Ref \\
\hline Yes & $3.86(0.65-32.36)$ & $3.31(0.14-183)$ \\
\hline \multicolumn{3}{|l|}{ Access site } \\
\hline Right femoral artery & Ref & Ref \\
\hline Left femoral artery & $0.56(0.09-3.68)$ & $1.29(0.07-42.14)$ \\
\hline \multicolumn{3}{|l|}{ Type of catheter } \\
\hline $7 \mathrm{Fr}$ & Ref & Ref \\
\hline $12 \mathrm{Fr}$ & $0.45(0.07-2.63)$ & $0.01(0.00-0.68)$ \\
\hline \multicolumn{3}{|l|}{ Target zone } \\
\hline 1 & Ref & Ref \\
\hline 3 & $1(0.18-5.65)$ & $0.68(0.06-7.62)$ \\
\hline \multicolumn{3}{|l|}{ Education } \\
\hline Educated & Ref & Ref \\
\hline Non-educated & $2.6(0.37-18.88)$ & $154.64(1.11-22.60)$ \\
\hline \multicolumn{2}{|c|}{ Hosmer \& Lemeshow goodness of fit test } & 0.941 \\
\hline AUC & & 0.836 \\
\hline
\end{tabular}

ISS: injury severity score, REBOA: resuscitative endovascular balloon occlusion of the aorta, AUC: area under the receiver operating characteristic curve. 
univariate (OR 1.00, 95\% CI 0.18-5.65), and multivariate (OR 0.68, 95\% CI 0.06-7.62) analysis. Finally, the non-education group had a higher risk of failure compared to the education group in the multivariate analysis (OR 154.64, 95\% CI 1.11-22.60) but not in the univariate analysis (OR $2.60,95 \%$ CI $0.37-18.88)$. The $p$-value of the Hosmer and Lemeshow goodness of fit test for this model was 0.941, and the area under the receiver operating characteristic curve was 0.836 , meaning that this LRA model adequately explains the data of this study (Table 3 ).

\section{DISCUSSION}

The main reason for REBOA in this study was intra-abdominal injury (54.2\%). However, pelvic bone fracture (45.8\%) and liver injury (20.8\%) were the first and second most common reasons for REBOA when single organs were considered, respectively. Six patients (25.0\%) had multiple injuries, and there was no significant difference between the educated and non-educated groups $(p=1.000)$. Ordoñez et al. [18], in their seven-case series report, suggested that the combination of REBOA and emergent resuscitative thoracotomy could be useful in pa- tients with non-compressible torso hemorrhage secondary to penetrating chest trauma. However, we performed REBOA only in patients with an injury below the diaphragm because REBOA is usually indicated in patients with injuries below the diaphragm [19], and performing REBOA in thoracic trauma patients with or without other torso injuries is debated [11].

Failure of the procedure was defined as when the REBOA balloon was not located in the desired target Zone during the first procedure. Knowledge of the anatomy of the aorta is required for performing REBOA. To perform REBOA, the aorta is divided into three Zones. Zone 1 is defined as the part of the aorta from the left subclavian artery to the celiac trunk. Zone 2 is from the celiac trunk to the lowest renal artery. Zone 3 is the part of the lowest renal artery to the aortic bifurcation [12]. We decided Zone 1 occlusion for patients with cardiac arrest or hemorrhagic shock arising below the diaphragm. We tried to avoid Zone 2 because it is considered to be a non-occlusion Zone. Zone 3 occlusion was used for patients with pelvic bone fractures without evidence of intra-abdominal hemorrhage $[20,21]$. In our study, REBOA has often been in an unintended position and has even been destroyed (Fig. 2). Furthermore, we described other Zones, in ad-

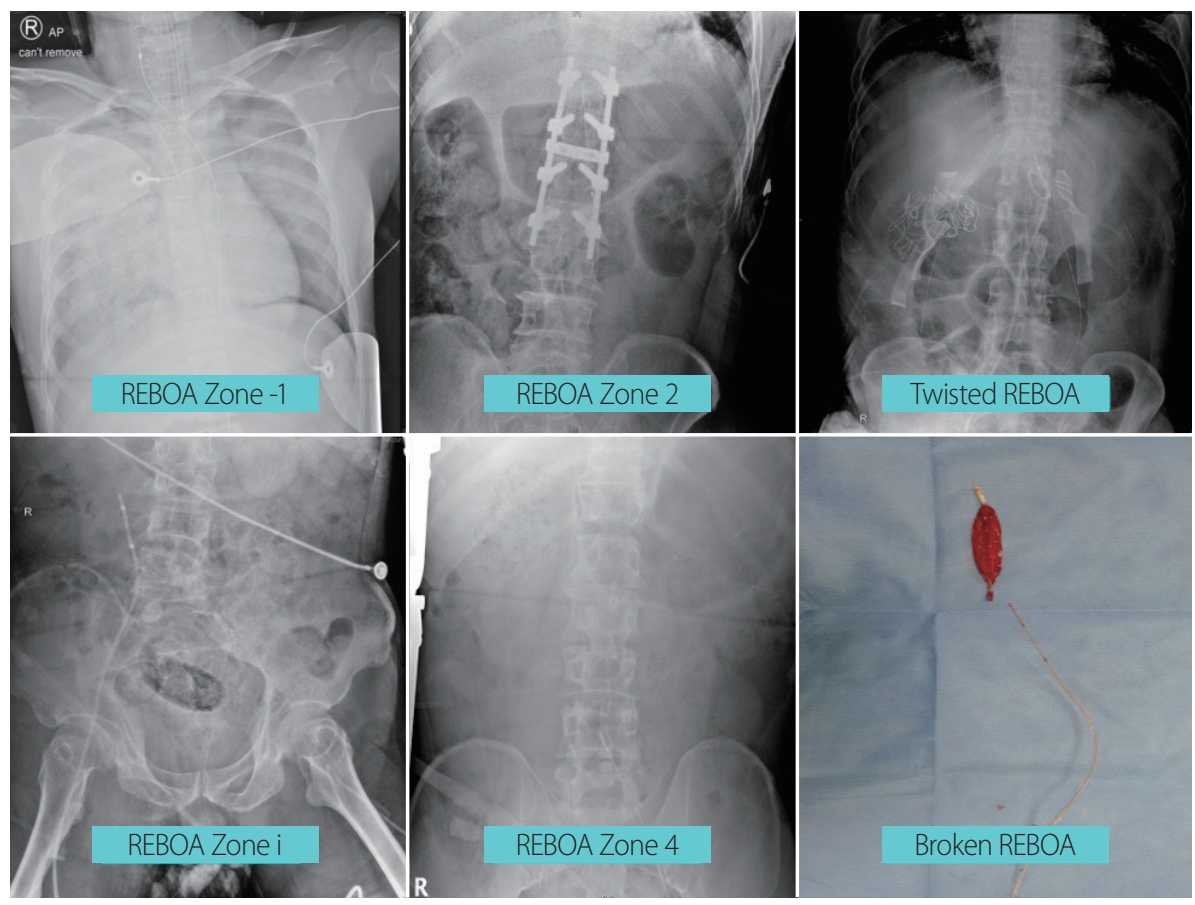

Fig. 2. REBOA in an unintended position and broken REBOA. REBOA: resuscitative endovascular balloon occlusion of the aorta. 
dition to the previously known Zones. Depending on the anatomical structure, Zone 0 , Zone -1, and Zone 4 were added and, if the inferior vena cava was entered, it was referred to as Zone i (Fig. 3).

As it is well known that a smaller diameter is associated with fewer access-related complications and therefore, safer $[3,16,17]$, we used 7 Fr or 12 Fr catheters in REBOA. Many complications related to the REBOA catheter must be considered. These include femoral arterial complications (disruption, dissection, pseudoaneurysm, hematoma, and thromboembolism), extremity ischemia, aortoiliac complications (intimal tear, dissection, and rupture), and bowel ischemia $[15,19]$. These complications occur due to physical damage inflicted on the accessing vessel and ischemia with inflammation caused by blockage of downstream blood flow $[15,22]$. To date, there is a lack of studies on the correlation between catheter diameter and the risk of procedural failure.

When we compared the educated and non-educatedn groups in the patients who underwent REBOA within our study, there were not many variables that showed signifi-

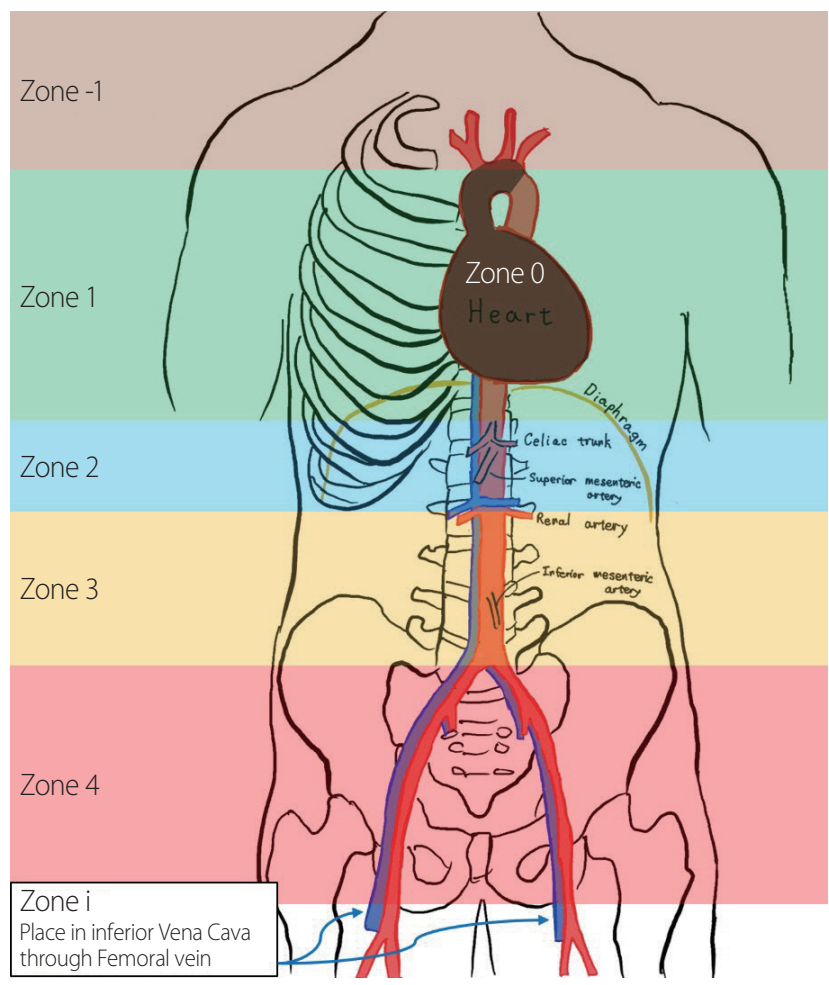

Fig. 3. New aortic Zones for resuscitative endovascular balloon occlusion of the aorta. cant differences between the two groups according to the Student's $t$-test and Fisher's exact test. However, we noted that the non-educated group failed more frequently than the educated group in the LRA model in which the occurrence of failure as the dependent variable. This was not statistically significant in univariate analysis. However, in the multivariate analysis, it is statistically significant and its effect size is reinforced. In addition, there is a protective effect on procedural failure in the $12 \mathrm{Fr}$ group compared to $7 \mathrm{Fr}$ group in the multivariate analysis. However, it cannot be easily concluded that there is a greater risk of failure than the $12 \mathrm{Fr}$ group. This finding is a contingency classified by education, the result of REBOA, and catheter type (Table 4). In the non-educated group, 8 of 9 cases (88.9\%) failed when the 7 Fr catheter was used, and 5 of 9 cases (55.6\%) failed with the $12 \mathrm{Fr}$ catheter. Interesting, all REBOA-educated physicians used the $7 \mathrm{Fr}$ catheter. There were 3 of 6 cases (50.0\%) with failure using 7 Fr catheters in the education group. Fisher's exact test was performed, and there was no significant difference between the variables (catheter and result) in both the education and non-education groups. Considering the data size of this study, it is appropriate to defer the judgment on whether the catheter type affects the success of REBOA.

REBOA is a time-dependent procedure and is mostly used in emergencies. REBOA's role is to buy the time to allow for subsequent treatment, such as surgery or angiographic embolization. For patients with a high risk of death $[3,23,24]$, it is very important to implement REBOA accurately and concisely, to reduce the patient's hemorrhagic burden even a little. Many studies have shown that a catheter with a smaller diameter is more favorable for patient safety compared to larger catheters $[16,17]$. If it is

Table 4. Contingency classified by education, the result of REBOA, type of catheter

\begin{tabular}{|lcccccc|}
\hline & \multicolumn{2}{c}{ Education } & & \multicolumn{2}{c|}{ Not-education } & \\
\cline { 2 - 3 } & Success & Failure & & Success & Fail & \\
\hline $12 \mathrm{Fr}$ & 0 & 0 & & 4 & 5 & 9 \\
$7 \mathrm{Fr}$ & 3 & 3 & & 8 & 15 \\
Total & 3 & 3 & & 5 & 13 & 24 \\
Fisher's exact test & $p=1.000$ & & \multicolumn{2}{c}{$p=0.294$} \\
\hline
\end{tabular}

REBOA: resuscitative endovascular balloon occlusion of the aorta. 
confirmed that the type of catheter affects the success rate of REBOA, education programs to increase REBOA success would become more important for every physician in the trauma center.

During the study period, the 7 Fr catheter was used after May 2018. Only one physician completed REBOA education. This study has limitations in that it does not consider the effects of inter-operator differences and it is a retrospective study in a single center. In addition, this study consists of a small number of patients, and no prior study has compared catheter diameter and procedural success rate. Therefore, further studies with more accumulated data are necessary.

\section{CONCLUSION}

REBOA is a technique for patients with life-threatening hemorrhagic shock. REBOA improves hemodynamic stability and enables treatment. It is useful in patients with blunt trauma. Therefore, REBOA is becoming important in Republic of Korea, where most trauma patients are affected by blunt trauma. However, the failure of REBOA is harmful to patients, and the risk of failure is increased when REBOA is performed by physicians without REBOA training. It is paramount that physicians in the trauma center or emergency department complete the REBOA education program.

\section{ACKNOWLEDGEMENTS}

We would like to thank Editage (www.editage.co.kr) for English language editing.

\section{REFERENCES}

1. Sanddal TL, Esposito TJ, Whitney JR, Hartford D, Taillac PP, Mann NC, et al. Analysis of preventable trauma deaths and opportunities for trauma care improvement in Utah. J Trauma 2011;70:970-7.

2. Tien HC, Spencer F, Tremblay LN, Rizoli SB, Brenneman FD. Preventable deaths from hemorrhage at a level I Canadian trau- ma center. J Trauma 2007;62:142-6.

3. Chung JS, Kim OH, Kim S, Jang JY, An GJ, Jung PY. Resuscitative endovascular balloon occlusion of the aorta in impending traumatic arrest: is it effective? J Trauma Inj 2020;33:23-30.

4. Kauvar DS, Lefering R, Wade CE. Impact of hemorrhage on trauma outcome: an overview of epidemiology, clinical presentations, and therapeutic considerations. J Trauma 2006;60(Sup$\mathrm{pl} \mathrm{6):S3-11.}$

5. Cannon JW. Hemorrhagic shock. N Engl J Med 2018;378:370-9.

6. Abe T, Uchida M, Nagata I, Saitoh D, Tamiya N. Resuscitative endovascular balloon occlusion of the aorta versus aortic cross clamping among patients with critical trauma: a nationwide cohort study in Japan. Crit Care 2016;20:400.

7. Matsumoto S, Hayashida K, Akashi T, Jung K, Sekine K, Funabiki $\mathrm{T}$, et al. Resuscitative endovascular balloon occlusion of the aorta (REBOA) for severe torso trauma in Japan: a descriptive study. World J Surg 2019;43:1700-7.

8. Brenner M, Inaba K, Aiolfi A, DuBose J, Fabian T, Bee T, et al. Resuscitative endovascular balloon occlusion of the aorta and resuscitative thoracotomy in select patients with hemorrhagic shock: early results from the American Association for the Surgery of Trauma's Aortic Occlusion in resuscitation for trauma and acute care surgery registry. J Am Coll Surg 2018;226:730-40.

9. Moore LJ, Brenner M, Kozar RA, Pasley J, Wade CE, Baraniuk MS, et al. Implementation of resuscitative endovascular balloon occlusion of the aorta as an alternative to resuscitative thoracotomy for noncompressible truncal hemorrhage. J Trauma Acute Care Surg 2015;79:523-30; discussion 530-2.

10. Byun CS, Park IH, Oh JH, Bae KS, Lee KH, Lee E. Epidemiology of trauma patients and analysis of 268 mortality cases: trends of a single center in Korea. Yonsei Med J 2015;56:220-6.

11. Bekdache O, Paradis T, Shen YBH, Elbahrawy A, Grushka J, Deckelbaum D, et al. Resuscitative endovascular balloon occlusion of the aorta (REBOA): indications: advantages and challenges of implementation in traumatic non-compressible torso hemorrhage. Trauma Surg Acute Care Open 2019;4:e000262.

12. Osborn LA, Brenner ML, Prater SJ, Moore LJ. Resuscitative endovascular balloon occlusion of the aorta: current evidence. Open Access Emerg Med 2019;11:29-38.

13. Hoareau GL, Tibbits EM, Beyer CA, Simon MA, DeSoucy ES, Faulconer ER, et al. Resuscitative endovascular balloon occlusion of the aorta: review of the literature and applications to veterinary emergency and critical care. Front Vet Sci 2019;6:197.

14. White JM, Cannon JW, Stannard A, Burkhardt GE, Spencer JR, 
Williams K, et al. Direct vascular control results in less physiologic derangement than proximal aortic clamping in a porcine model of noncompressible extrathoracic torso hemorrhage. J Trauma 2011;71:1278-86; discussion 1286-7.

15. Ribeiro Junior MAF, Feng CYD, Nguyen ATM, Rodrigues VC, Bechara GEK, de-Moura RR, et al. The complications associated with resuscitative endovascular balloon occlusion of the aorta (REBOA). World J Emerg Surg 2018;13:20.

16. Matsumura Y, Matsumoto J, Kondo H, Idoguchi K, Ishida T, Kon Y, et al. Fewer REBOA complications with smaller devices and partial occlusion: evidence from a multicentre registry in Japan. Emerg Med J 2017;34:793-9.

17. Teeter WA, Matsumoto J, Idoguchi K, Kon Y, Orita T, Funabiki $\mathrm{T}$, et al. Smaller introducer sheaths for REBOA may be associated with fewer complications. J Trauma Acute Care Surg 2016;81:1039-45.

18. Ordoñez CA, Parra MW, Manzano-Nunez R, Herrera-Escobar JP, Serna JJ, Rodriguez Ossa P, et al. Intraoperative combination of resuscitative endovascular balloon occlusion of the aorta and a median sternotomy in hemodynamically unstable patients with penetrating chest trauma: is this feasible? J Trauma Acute Care Surg 2018;84:752-7.

19. Brenner M, Bulger EM, Perina DG, Henry S, Kang CS, Rotondo MF, et al. Joint statement from the American College of Surgeons Committee on Trauma (ACS COT) and the American
College of Emergency Physicians (ACEP) regarding the clinical use of resuscitative endovascular balloon occlusion of the aorta (REBOA). Trauma Surg Acute Care Open 2018;3:e000154.

20. Tibbits EM, Hoareau GL, Simon MA, Davidson AJ, DeSoucy ES, Faulconer ER, et al. Location is everything: the hemodynamic effects of REBOA in Zone 1 versus Zone 3 of the aorta. J Trauma Acute Care Surg 2018;85:101-7.

21. Brenner M, Hoehn M, Pasley J, Dubose J, Stein D, Scalea T. Basic endovascular skills for trauma course: bridging the gap between endovascular techniques and the acute care surgeon. J Trauma Acute Care Surg 2014;77:286-91.

22. Sadeghi M, Dogan EM, Karlsson C, Jansson K, Seilitz J, Skoog P, et al. Total resuscitative endovascular balloon occlusion of the aorta causes inflammatory activation and organ damage within 30 minutes of occlusion in normovolemic pigs. BMC Surg 2020;20:43

23. Özkurtul O, Staab H, Osterhoff G, Ondruschka B, Höch A, Josten $\mathrm{C}$, et al. Technical limitations of REBOA in a patient with exsanguinating pelvic crush trauma: a case report. Patient Saf Surg 2019;13:25.

24. Tiba MH, McCracken BM, Cummings BC, Colmenero CI, Rygalski CJ, Hsu CH, et al. Use of resuscitative balloon occlusion of the aorta in a swine model of prolonged cardiac arrest. Resuscitation 2019;140:106-12. 